\title{
Pastiche Plus; styles, philosophies and advanced design skills
}

\author{
Nathan Middelham and Wouter Eggink
}

University of Twente

\begin{abstract}
This paper describes the Pastiche+ learning method for design skills on a master education level. By using philosophies and stylistic elements of art and design movements the method tries to extend ones skill and knowledge about design tools, principles and processes in an elaborate way. The paper describes the purpose and context of the method in the introduction and method section. Pastiche+ is then put to the test in a case study around graphic design and communication. This resulted in a profound set of posters, advocating using the train. After an extensive reflection and evaluation of the process and results we conclude that the method can be considered effective as a high level individual skills developer. The research results about communication are inherently subjective, however the insights from the personal reflection can be valuable in informing the design process of every designer who has a message to tell.
\end{abstract}

Keywords: Advanced design skills , Graphic design, Visual communication, Design movements, Design philosophy.

\section{Introduction}

In this paper we introduce a learning method for designers that uses art and design movements throughout the ages as a source of new knowledge, philosophies, visual language and methods. The learning method is based on the pastiche. A work can be called pastiche if it imitates a style from another work, artist or era, and unlike parody it does not criticize. The proposed method lets the design practitioner do pastiche, however also includes the movements defining philosophy and circumstances as additional elements in the design practice, hence the name Pastiche+.

Pastiche+ is developed as a learning technique for design skills in a higher education environment. Especially in the context of master education, merely skills training is not preferred (Q.A.N.U., 2014). We therefore introduced several elements of reflection and research in the different steps of the technique to make it suitable as a Capita Selecta for the Master Industrial Design Engineering. The result can be seen as an approach that is a combination of the reflective practitioner by Schön (1983) and the Research Through Design methodology (Findeli, 2010; Frayling, 1993).

In the approach, through the analysis of various styles, philosophies, circumstances and possible interpretations, an artistic playing field is created. The main goal of Pastiche+ is to let the practitioner explore this playing field, which is done by investigating the nature of multiple movements, using the movement related knowledge to design with, and evaluating the different processes and results.

The Pastiche+ method is relevant for designers that seek to explore and expand their knowledge and skills. Someone who undergoes this method is assumed to be overloaded with new ways of thinking and working rather than focusing on what one already knows. Additionally, the designer will increasingly be able to put stylistics elements in their historic context.

This paper explains the individuals steps of our Pastiche+ approach in the Method section and provides a summary of the Case Study along two of the chosen movements. The case study will be reflected upon in the Discussion section, followed by the Conclusion.

\section{Method}

One of the teaching principles the Pastiche+ is based upon is repetition. We think that doing a Pastiche+ cycle with, for example, just one movement would not train a practitioner enough to use and reflect on the effects of movements. The Pastiche+ should be seen as a skill of using art and design movements for one's own practice, it is about being inspired and doing something with that inspiration. In such way, it fits in a methodical approach of using insights from design history in contemporary design practice (Eggink, 2009, 2016). The actual process of the Pastiche+ learning method consists of seven steps: 
- Selection of movements and message

- Movement research

- Ideation

- Designing and iteration

- Personal evaluation

- Exhibiting and survey

- Survey evaluation and conclusion

During the entire process, two variables are controlled for: [1] The designed artefact (e.g. poster, video, website) has to be consistent across all movements. [2] The designed artefacts need to have the same purpose or goal (e.g. communicate, explain, or persuade).

\section{Step 1: Selection of movements and message}

The selection of the movements is an exploration in itself, the Pastiche+ practitioner is invited to select his or her own preferred topics. However, there are guidelines that are assumed to aid the explorative aim of the method:

- Choose many movements, repetition is more important than finesse;

- Choose movements with a variance in time in history, country of origin, and stylistic elements;

- Choose movements with a variance in scope of the definition (e.g. Modernism versus Bauhaus).

Also note that one could play with the variance of variances, it could be evenly interesting to compare two largely different movements as it would with two which are much alike.

The purpose should be achieved in the manner the movement dictates, thus it can happen that the purpose could be entirely inconceivable when it is one of the defining traits of that art movement. It is recommended to select a topic that could relate to multiple art movements, a topic that for example only relates to social networks would not work well with movements that mainly focus on nature. However, it could prove to be an interesting angle to work with, as the method is about exploring the playing field.

\section{Step 2: Movement research}

For every movement, one or multiple relevant books or other sources should be consumed and summarized, later to be used as inspiration. Movement associated pieces of work should also be collected and potentially be used as reference.

\section{Step 3: Ideation + step 4: Designing and iteration}

Ideation starts by doing short experiments with the movements process, motives and styles, in order to understand the implicit implications. Then these experiments are set aside, and compositions are made. These compositions will be inspired by the philosophy of the movement, they dictate which motives are selected, how they are placed and how they are communicated. After compositions are made, they will serve as inspiration of the creation process, this process is influenced by the art movement and selected motives. Artists can select their preferred tools, for the case study in this paper the tools photography, Adobe Photoshop, -Illustrator, -InDesign and Blender were used.

The next iteration is applying the style of the movement. Some movements have strict defining stylistic elements (e.g. Swiss School) while others do not (e.g. Romanticism). When it is the first of the two, the stylistic characteristics of the style will be used, when it is the latter, one or more artists that are associated with the style will be used as reference. If possible, the results should be discussed with a design teacher or peer and iterated upon.

\section{Step 5: Personal Evaluation}

The personal reflection looks at the effects of the different movements on the act of designing. As reflection is an important aspect of learning (Bishop-Clark \& Dietz-Uhler, 2012), it is also advised to do this in a structured manner (Procee \& Visscher-Voerman, 2004). In the Pastiche+ method, the design process and results are therefore reflected upon alongside a predefined set of qualities that are related to the chosen artefact and the purpose.

\section{Step 6: Exhibition and survey}

The exhibition is an invitation for others to view and give their opinion on your designs. This is done for motivation and for having an additional source of insights. 
To gain these insights a survey has to be filled-in by guests of the exhibition. The survey can have both qualitative and quantitative statements to have a variety in kinds of insights. The set of statements should of course also be related to the chosen artefact and purpose, and can be comparable to the set of qualities from the personal evaluation.

\section{Step 7: Survey evaluation and conclusion}

The answers of the survey of step 6 are going to be reflected upon. Results will be compared, and new insights will be written down. This should lead to a better understanding of the acquired design skills in relation to the movements, philosophies, designs and the purpose.

\section{Case Study}

In the case study, the design skill to develop was graphic design. The artefact that was chosen as subject to be designed was posters, and the chosen purpose was communication. The message to be communicated through the posters was chosen to be: "Take the train because it is good for nature." Where the message implies that compared to other modes of transport the train damages the earth less.

This message was selected because it could broadly relate to society, politics, nature and technology, which are subjects that are often used in art and design movements. In the design process the philosophy aspect of the movements dictates which part of the message needs to be highlighted. Some art movements will focus on the train part more, others on the nature part.

Chosen movements were: Romanticism, Ukiyo-E, Futurism, Constructivism, Dadaism, Swiss School, Pulp (paperbacks), Post-Modernism, and Pop-Art. Romanticism was chosen because of its relative old age. Ukiyo-E was included to incorporate a movement that did not inherit its characteristics from western culture. Futurism, constructivism and Dadaism were chosen because of their visual qualities and closeness in time. Swiss School (or International Style) was chosen because of its lasting influence on graphic design. Pulp, and specifically Pulp paperbacks, was chosen because of its unique stylistic elements and focus on advertisement. Post-Modernism was chosen because it is a large umbrella term that incorporates many styles, unlike very specific styles like Swiss School and Pulp paperbacks. Finally Pop-Art was chosen because its visual style is still widely used.

\section{Case study goals}

With a case study the teaching method is tested. The goals are to explore and reflect on the various qualities of the method, finding its up- and downsides, and to identify points of improvement.

\section{Movement research and Design}

For every chosen movement style research was performed, based on literature. Both visual characteristics and philosophy of the movements were incorporated in the investigation. Because of the size limits of the paper we describe only two examples of the findings of such research, followed by the designs that were based on these findings.

\section{Romanticism}

Romanticism has multiple defining characteristics. Some define it as a Gothic novel genre while others would define it by their perception of Catholicism. There even exist decision models that place a piece of work on the Romantic spectrum (Ferber, 2010).

Although there are so many differences, most Romanticists tend to focus on its new way of viewing and living with God. At the time, the dominant interpretation was that one God ruled all, this was portrayed by the older Classic movement. A growing number of philosophers philosophized that god was not only somewhere up in the sky, but was everywhere, and more importantly, everything. He was the sky above and the people the ants below. Some scientists used this philosophy to research nature without the obstruction of the church (Ferber, 2010). This version of Romanticism was used in this project.

Like these philosopher and scientists, the Romantic artists focused on nature, discarding the holy compositions of the Classicists. Romanticism often saw emotion as something pure and holy, promoting introspection and letting emotions flow, choosing emotion over ratio.

\section{Style}

Romanticism is more about their philosophical interpretation of God, or about letting their emotion flow, it does not have defining rules about style. Stylistics elements differentiate from medium to medium and 
artist to artist (Wolf et al., 2010). The painter Francisco Goya and Henry Fuseli focused more on the inner emotional aspect (depicted respectively with the Black paintings series and The Nightmare), but other known painters like William Turner and Caspar David Friedrich focused more on large terrific environments (depicted respectively in Snow Storm and Wanderlust). Their paintings are often described as sublime, which the poet William Wordsworth defines as "Arouses terror at the vastness and wild, ungovernable nature" (Busch, 2017).

\section{Design}

William Turner was used as most important influence for the poster design (Figure 1). His paintings often include a sun that acts as the biggest source of energy. He often paints terrifying storms and plays with the focus of the eye by adding blurry brushwork.

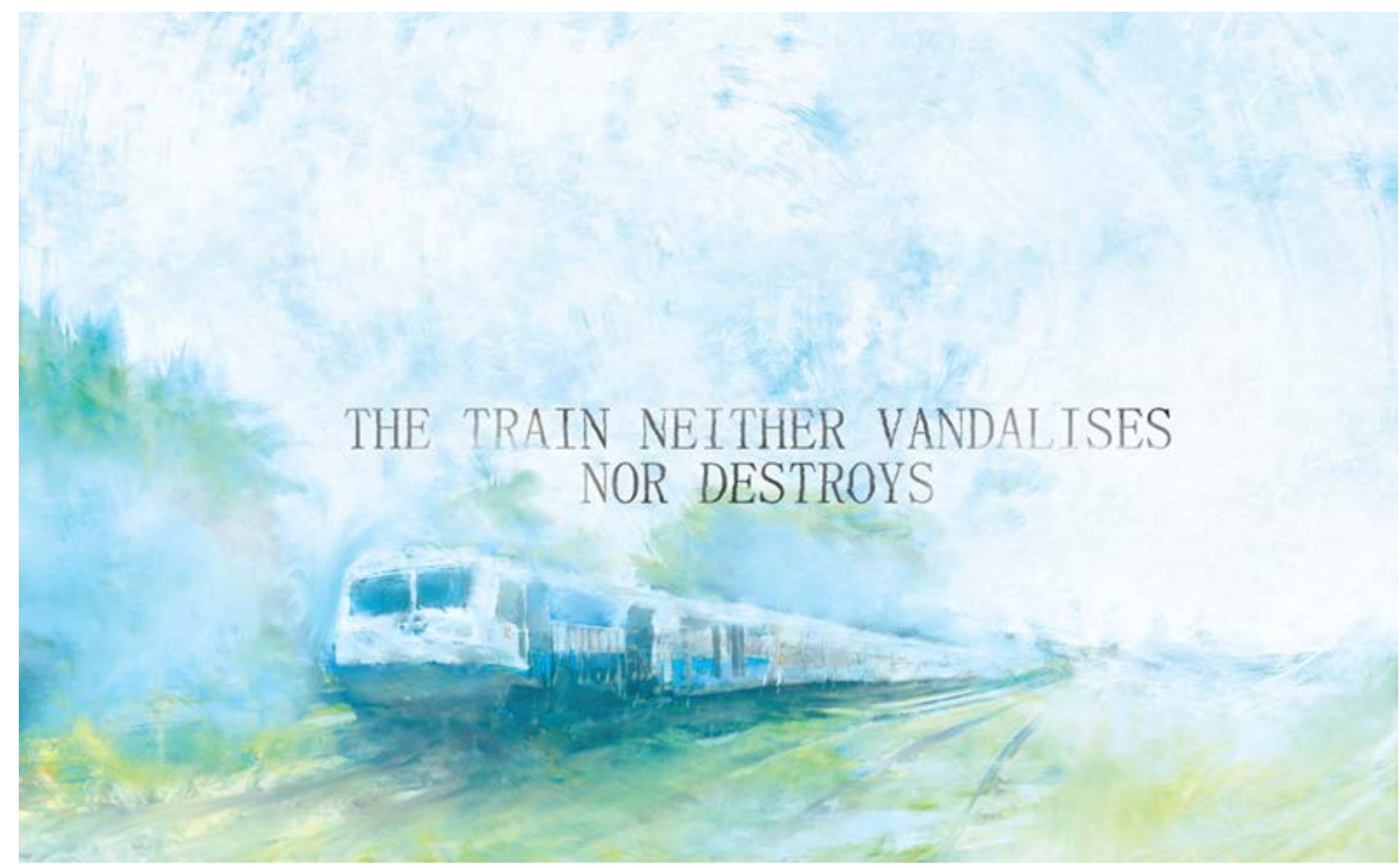

Figure 1: Poster design "Romanticism"

This poster tries to merge the train with nature, saying in a visual manner, that the train and the nature are not different from each other and can live side by side. Therefore, a train passenger should not feel guilty, instead rather pleased. The merger of nature and train is done by blending their colours, blurring their edges and decreasing the contrast between them.

The text pushes the message a little further, "the train neither vandalizes nor destroys" implies that other ways of transport do vandalize and are therefore worse. A dramatic tone was chosen, instead of a rational argument, because of the emotional side of Romanticism.

\section{Constructivism}

Constructivists chose order over chaos, ratio over emotion and collective over individual worth. They saw the new machinery as a way to enter new domains and go across the limits of the human body. Constructivism often celebrated Communistic principles but it would be a mistake that all works are driven by them (Hötte et al., 2013).

\section{Style}

New Typography liberated typography from classical rules, adopting Modernistic principles. It was adopted by multiple movements (Futurism, Dadaism, Constructivism). Constructivists choose to use thick geometric sans-serif type and often placed them diagonally, both in 2 and 3 dimensions.

Like New Typography, New Objectivity liberated photography from classical rules, also adopting Modernistic principles. It was also adopted by multiple movements, Constructivism being one of them. This new look on photography was made possible by the emergence of technology (Hötte et al., 2013). Now artists, like Paul Schuitema, could change things up like neglecting the usage of a clear horizon, not 
having a breast or eye perspective and experiment with different camera distances (Maan, 2017). Other factors that were used in Constructivism were Euclidian geometry, differentiating brightness, precise and streamlined reality.

\section{Design}

Because most work is a celebrates the machine, in most work traces of machinery can be found. This can be either done by showing marks that reveal the usage of the machine but it was mainly done by having machine-like geometry. The machine parts of the poster (portrayed by the train, track and typography) have nature at their centre (portrayed by the tree), saying in its subtext that this machinery has nature at its hart. The text "Mother Earth Machine" then declares that this is a machine of the world, implying that it would not harm it (Figure 2).

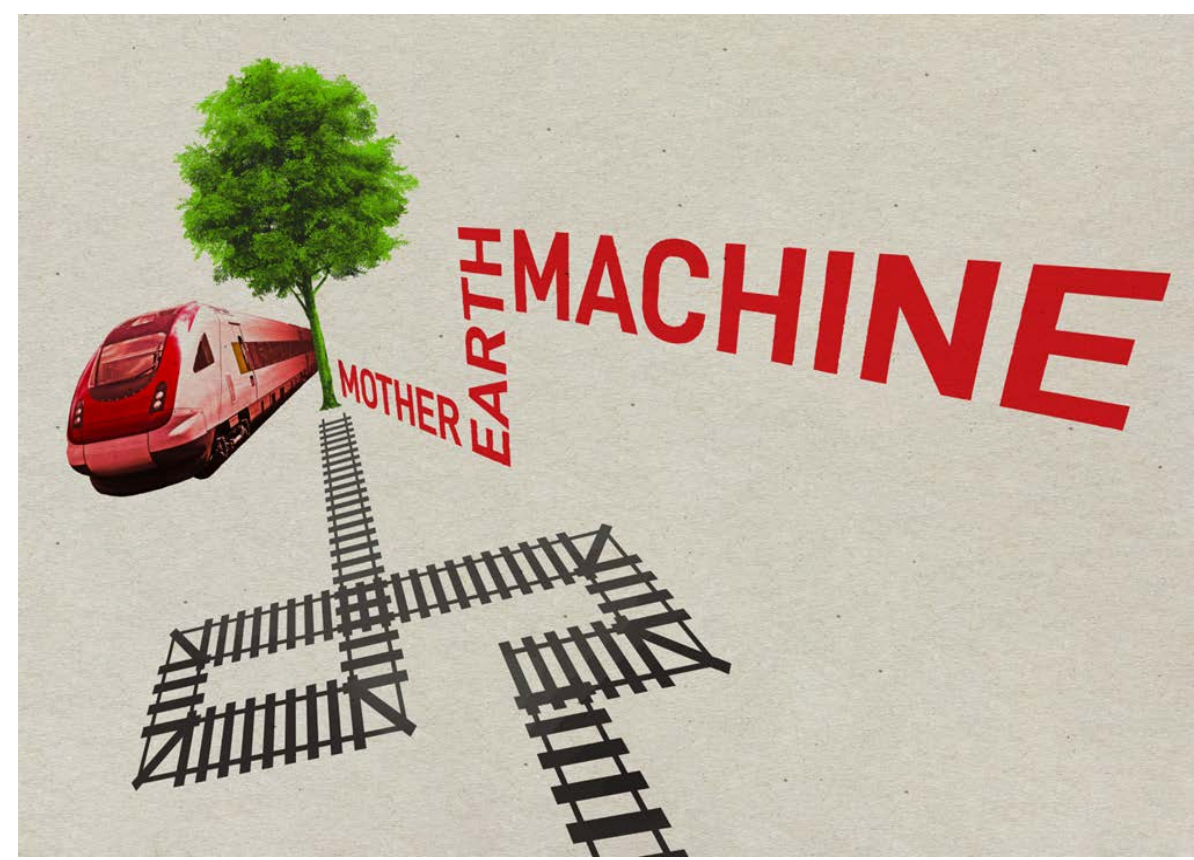

Figure 2. Poster design "Constructivism".

The poster uses New Objectivity by placing images without the classical rules of positioning, scaling and colouring. It also uses a little bit of New Typography, by adding perspective to the text and using an unconventional manner of placing. The composition uses a horizon which is off and a pointed perspective, imitating Nina Krogan's Composition 2, which is a Supremacist painting, however that style does share visual qualities with Constructivism (but not its fundamental philosophy). The composition is also heavily influenced by the usage of photography in Dick Schuitema's work.

\section{Design Results}

In line with the methods basic rule of repetition, a total of nine posters was designed. The poster designs resulting from six of the other movements are pictured in figure 3 and 4 . The poster associated with Ukiyo-E is visible in the impression of the exhibition in figure 5 (left).
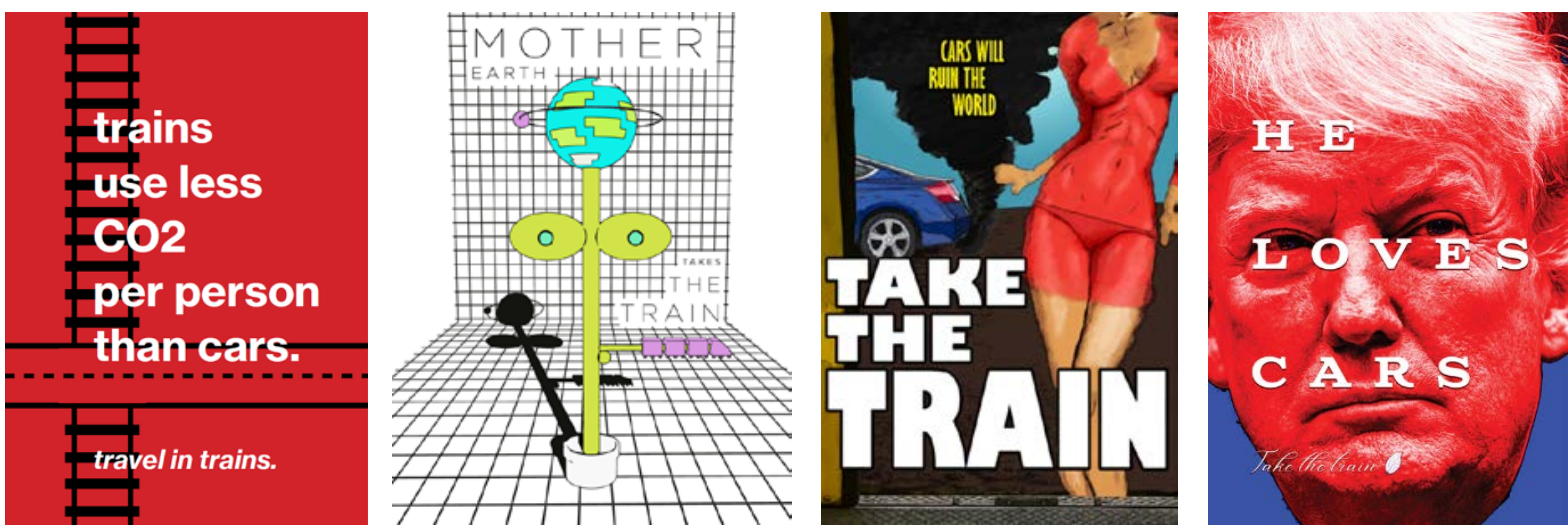

Figure 3, Poster designs for respectively "Swiss School”, "Post-Modernism” (Memphis), "Pulp”, and "Pop-Art”. 


\section{Personal Evaluation}

The personal reflection looked at the effects of the art movement on the act of designing a poster. To structure the reflection process, six qualities were thoroughly compared for each movement.

\section{Ease of creating meaning}

This quality is about how easy it was to combine the philosophy and style to create and communicate the idea that would communicate the message. A movement could be either very direct in communicating the message, very indirect or somewhere in-between.

Swiss School, Pulp-paperback and Pop-Art were easy to create meaning with. What they have in common is a clear usage of elements to portray meaning. Swiss School and Pulp-paperbacks have this inherit quality because they were made for advertisement (Ruder, 1959; Schreuders, 1981). Pop-Art uses popculture (thus also advertisement) which means the designer has a wide variety of already created images and ideas with meaning, which makes it easy.

Dadaism was hard to create meaning with. The first reason is that I wanted to add randomness like Tristan Tirza with his poems (Tirza, undated). The second reason is the anti-commerce and anti-art side of Dadaism, making it hard to let the poster have a persuasive commercial meaning. In the same manner, many Post-Modernists went with the 'function follows form' mantra which made it hard to create meaning with. However, the art movement did have tools to work with, like the combination of references from 'high' and 'low' culture (Joris et al., 1984) and the theory of Dual Coding (Jencks, 1984).
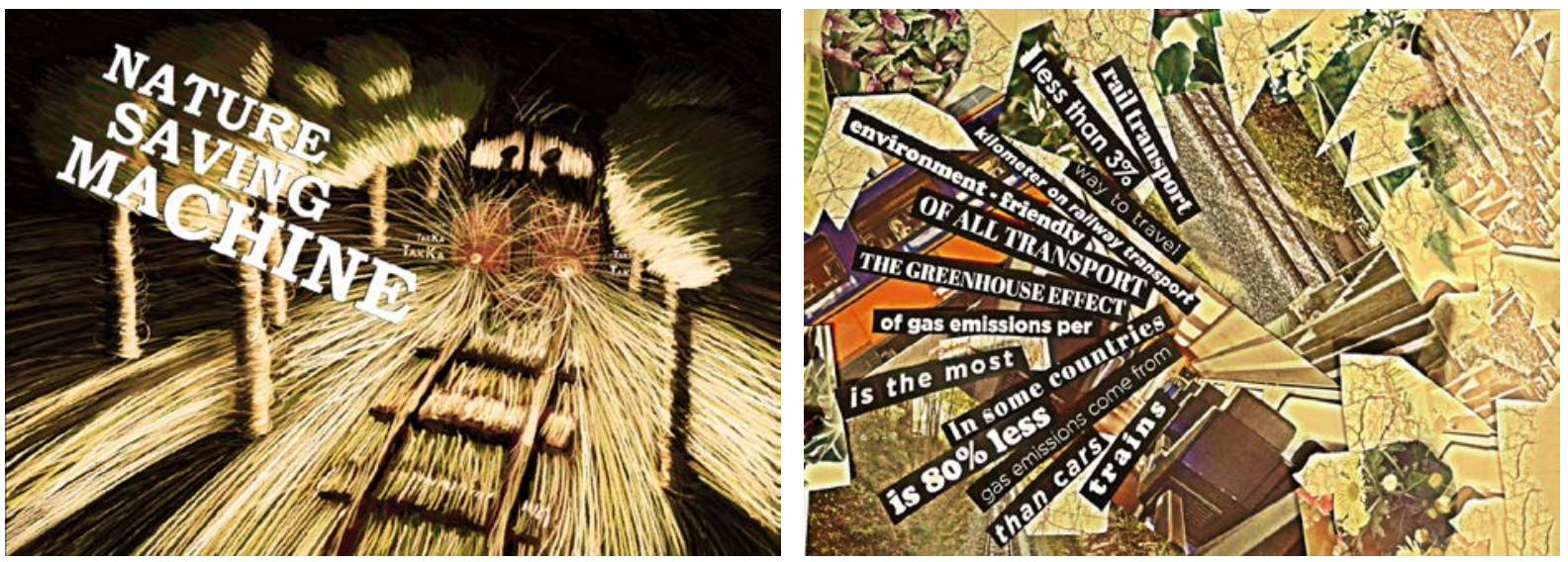

Figure 4. Poster designs for "Futurism" (left) and "Dadaism" (right).

\section{Ease of creating composition}

This quality is about transforming the message into stylistic elements that have to be placed. Some art movements have strict composition rules, while others do not. Both could actually either aid or hinder the crating process.

Numerous styles (Romanticism, Ukiyo-E, Dadaism, Swiss School and Pop-Art) were easy to create composition with. Romanticism and Ukiyo-E were easy because they were mostly filled with landscape (Ferber, 2010; Schlombs, 2007). Dadaism was easy because meaning was largely non-existent which made the composition more about visual play. Swiss School was the easiest to design for because it followed the grid structure method (Müller-Brockmann, 1999). Pop-art was easy because the object of popular culture needs the most attention, all the other parts just need a way of being there without taking away the attention.

Because Post-Modernism is mainly about style (Adamson \& Pavitt, 2011) it should have been an easy movement to create a composition for, however it dealt with many stylistically different geometric forms, making it hard to tell a story while maintaining balance in the composition. Both Futurism and Constructivism are a lot about machinery (Martin, 2005; Hötte et al., 2013), making it hard to create a composition which included nature.

\section{Ease of replicating the style}

After the philosophy is used and the composition is created the design process goes through a stylistic phase that tries to replicate the style of an artist of the movement. Some of them require a lot of artistry, 
with for example a lot of painted detail, while others use techniques that are quicker to apply, like assemblage.

Ukiyo-E, Swiss School and Pop-Art were easy to design with. Ukiyo-E's style is easy to replicate because the stylistic elements are simple, however, it does need a lot of detailing. Swiss School made it easy, their stylistic elements are limited and the grid system makes it simple to put together. Pop-Art was easy because it has no inherit style, but copies styles from popular culture. In that sense, Pop-Art is often already pastiche. Post-Modernism was hard because Memphis mainly designed physical products, and the poster would only be in the two dimensions. Also the 'Universal Dynamism' of Futurism was a difficult style to master.

Dadaism was contradictory, Dadaists used a lot of randomness but their work did seem to have a kind of order to it. Making the piece was easy because of mixing randomness and order, but questions about if the philosophy is applied right do remain. Assuming there even is a way, because Dada is also anti-Dada (Elger, 2004).

\section{Ease of creating impact}

This quality is one of the more subjective ones. It is about how doable it is to create images that captivate people in a consumeristic context. In this context it is assumed, for the sake of simplicity, that a design should be readable from afar and have a high amount of contrast to do so.

Dadaism, Swiss School, Pulp-paperbacks and Pop-Art had a style that was helpful in creating impactful images. Dadaists and their events (e.g. the ones in Circus Voltaire and Berlin) and other works (e.g. Marcel Duchamp's Fountain), tried to shock the perceiver and therefore used big contrasting imagery. Swiss School has a style that is crafted to create impactful imagery with the least amount of effort and time. Pulp-paperbacks thrived on shocking the perceiver, sometimes even misrepresenting the actual content, so that the consumer bought one of their novels. Pop-Art was easy because one only had to find the impactful imagery in popular culture and give it the main stage.

Romanticism was terrible to design with concerning impact, while the reference paintings often seemed too smooth.

\section{The pleasure in creating}

This quality is about if the act of creation was something that was enjoying and worth doing.

Ukiyo-E, Dadaism and Post-Modernism were fun to create with. Ukiyo-E is a method that is relaxing, it is forgiving and the repetition of drawing small details makes one forget the time. Dadaism was fun because it did not have a wrong or right way of doing it, making the process freeing and effortless. Post-Modernism had a difficult part which was finding the right forms, however, it was made highly pleasurable by denying any Modernistic process.

Swiss School's method was too methodological to have the pleasurable creative freedom. Pop-Art was fun to find the right images with, and rewarded you quickly with results but proved itself too simple to be a fulfilling process.

\section{The perceived duration of the production}

This quality is about how productive a style was perceived in terms of design per hour ratio.

Swiss School and Pop-Art lend themselves for quick production. You might say the first was made for it, with methods like the grid system that helped making the right decisions fast. Pop artists re-use a lot of work from other people, sometimes not even taking the time to remix it. This made for fast production, where the most time was spend finding the right imagery.

The other styles were less 'productive'. Post-Modernism took a long time to get the story told in the complex 3-dimensional geometry while the artwork of Pulp-paperbacks demanded a lot of artistry. UkiyoE took a very long time for drawing all the details and Romanticism to execute William Turner's style, which arguably still is not really achieved. With Dadaism it took time because of the multiple phases, but because there was no 'bad' way of doing there was no stress, which made it perceived as short.

\section{Survey Evaluation}

To gain more insight in the effects of the different movements on the design and communication of the message, the posters were presented to an audience in a small one-day exhibition (figure 5). Visitors were asked to fill in a survey for one or more posters. In this case, a total of 38 surveys were filled with quantitative and qualitative feedback. The results were then summarized and used to either confirm, 
enhance, or reject the conclusions of the personal reflection. This results added to the research through design aspect of the project, it turned out for instance that the Pulp poster was much disliked because of the sexist connotations of the 'philosophy' of the movement. The message of the Swiss School poster was intentionally the most clear and the Romanticism poster was surprisingly liked the most.
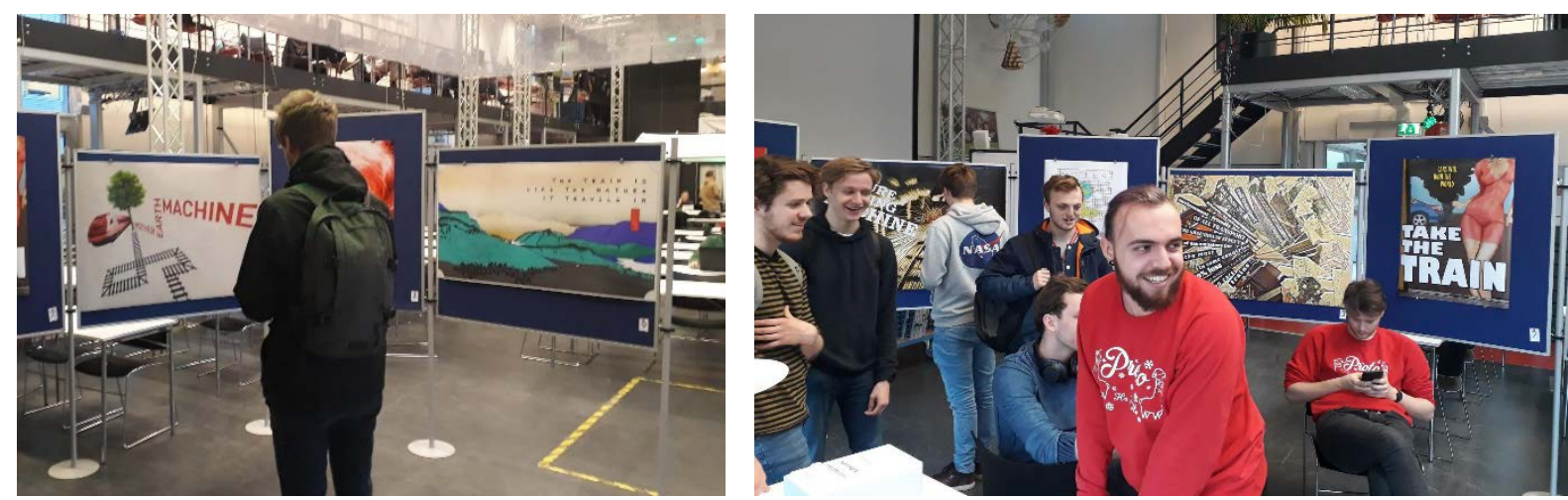

Figure 5. impressions of the poster exhibition, organised for the survey evaluation.

\section{Discussion}

In the case study, Pastiche+ proved to be excellent for exploring different design methods and styles. The circumstances and philosophies of the movements also helped explain why some style elements are the way they are, increasing the applicability when a practitioner decides to use them. In that sense it helped improve the designers 'design sense', which could be applied in other projects. The reflection and evaluation also helped to gain insight in the 'design opportunities' of the different movements' styles and philosophies. However, the method's result will be always highly depended on the practitioner. Thus, to gain academic merit, multiple case studies need to be done, evaluation and compared, preferably with more controlled values.

Movements had drastically diverging views on the design process, this helped in evaluation each style because they could be compared. This variance of chosen movements felt contributing to the explorative aspect of Pastiche+. However, the amount of movement often felt overwhelming, processing every movement proved to be time-intensive, which could hinder the time for repetition which is one of the goals of Pastiche+. A solution could be to lower the amount of movements and increase the number of designs per movement, in that case a practitioner needs less time to research and would thus have more time to spend on making designs and reflecting.

It is hard to capture all facets of an art or design movement, there are diverging historic views plus a variety of possible perspectives. However, the research of the movements as philosophies, rather than as mere styles added much to the abstraction level of designing and the quality of the results. This is best visible in the different ways in which the intended message is communicated and integrated in the visuals, from very direct in the Swiss School poster to rather 'hidden' in Romanticism.

\section{Conclusion}

In this paper, the Pastiche+ method was described, then examined by a case study and discussed in the end. The Pastiche+ method showed potential as a learning tool for extending one's knowledge and skill in graphic design and visual communication. In the design case, the method did execute its goal of letting a participant explore the playing field created by the various elements of the art and design movements. The research results are inherently subjective, however the insights from the personal reflection can be valuable in informing the design process of every designer who has a message to tell. 


\section{References}

Adamson, G. \& J. Pavitt (2011), Postmodernism: Style and Subversion, London, V\&A Publishing.

Bishop-Clark, C., \& B. Dietz-Uhler (2012). Engaging in the Scholarship of Teaching and Learning, Sterling, Virginia (US): Stylus.

Busch, W. (2017). De Romantiek In het Noorden: van Friedrich tot Turner [Romanticism in the North: from Friedrich til Turner], Groningen, Uitgeverij Wbooks \& Groninger Museum.

Eggink, W. (2009). A Chair to Look to the Moon: What We Can Learn from Irrational Design History for Contemporary Design Practice. Design Principles \& Practices: an International Journal, 3(1), 103-114.

Eggink, W. (2016). Design History Education in the Netherlands: the Historic, the Cultural, and the Methodical. , Proceedings of the Nordic Forum For Design History Studies Conference 2016: Design Education In The Nordic Countries, Aalto University School of Arts, Helsinki, Finland, 23-24 Sept.

Elger, D. (2004), Dadaïsme [Dadaism], Berlin, Taschen.

Ferber, M. (2010). Romanticism: A Very Short Introduction, Oxford University Press.

Findeli, A. (2010). Searching for Design Research Questions: Some Conceptual Clarifications. In: R. Chow, W. Jonas \& G. Joost (Eds.), Questions, Hypotheses \& Conjectures; Discussions on projects by early stage and senior design researchers (pp. 278-292): iUniverse.

Frayling, C. (1993). Research in Art and Design. Royal College of Art Research Papers, 1(1), 1-5.

Hötte, D. W. et al. (2013), Utopia 1900-1940: Visies op een Nieuwe Wereld [Utopia 1900-1940: Visions of a New World], Rotterdam, nai010.

Jencks, C.A. (1984 (1977)). The language of Post-Modern architecture, London: Academy Editions.

Joris, Y., et al. (1984). Memphis-Design, 's Hertogenbosch: Dienst Beeldende Kunst.

Maan, D. (2017). Paul Schuitema: Visual Organizer, Rotterdam, nai010.

Martin, S. (2005), Futurisme [Futursim], Berlin, Taschen.

Müller-Brockmann, J. (1999), Grid Systems, Salenstein (Switzerland), Niggli Verlag.

Procee, H., \& I. Visscher-Voerman (2004). Reflecteren in het onderwijs: een kleine systematiek. [Reflection in education: a small systematics]. VELON magazine for teacher training, 25(3).

Q.A.N.U. (2014). Industrial Design, Faculty of Engineering Technology, University of Twente. Q0441. Utrecht, Quality Assurance Netherlands Universities.

Ruder, E. (1959), The Typography of Order, New York, Allworth Press.

Schlombs, A. (2007), Hiroshige 1797-1858, Berlin, Taschen.

Schön, D. (1983). The Reflective Practitioner: How professionals think in action. , New York: Basic books.

Schreuders, P. (1981), Paperback, U.S.A.: Een Grafische Geschiedenis 1939-1959 [Paperback USA: A Graphic History 1939-1959], Amsterdam, Loeb Uitgevers.

Tirza, T. (undated). How to Make a Dadaist Poem, original work. via: https://fleursdumal.nl/mag/tristantzara-to-make-a-dadist-poem , accessed 12 May 2019.

Wolf et al., N. (2010). Romantiek [Romanticism], Berlin, Taschen. 